\title{
Age related metric changes in the hyoid bone
}

\author{
${ }^{1}$ Dr. Amrutha Roopa Ramagalla, ${ }^{2}$ Dr. Pulluri Sadanandam, ${ }^{3}$ Dr. T K Rajasree \\ ${ }^{1 \& 3}$ Department of anatomy, Osmania Medical College, Hyderabad, Telangana, India \\ ${ }^{2}$ Department of Community medicine, Kakatiya Medical College, Warangal, Telangana, India
}

\begin{abstract}
The age related metric changes in the hyoid bones were investigated directly. 4 measurements were performed on 83 hyoid bones from autopsy cases of known age and sex. The specimens were selected out of 350 medico legal cases in the age group of 15 - 75 years. Some of the hyoid bones obtained were damaged particularly those of hanging and strangulation cases. So, they were excluded from the study. Altogether 56 are male and 27 are female hyoids. Estimation of the age is possible in male hyoids only. The Mean, Standard deviation and level of significance of all the four parameters of the hyoid bone were calculated using the standard statistical method. The readings of mean $\pm S . D$ of different parameters are statistically significant $(p<0.001)$.
\end{abstract}

Keywords: hyoid bone, age estimation, morphometry, greater cornu.

\section{Hyoid Bone \\ Definition:}

\section{Introduction}

The hyoid bone is a mobile bone that is situated at the front (anterior) part of the neck between the jaw bone and the thyroid cartilage ${ }^{(4)}$.

\section{The Location of the Hyoid Bone}

The hyoid bone is located in front of the cervical spine (the bones of the neck). It resides at the level of the 3rd cervical vertebra. It attaches, by means of ligaments, to a projection of bone called the styloid process, which extends from the temporal bone. The hyoid bone is firmly secured to the thyroid cartilage ${ }^{(4)}$.

Segments: The bone consists of a central part called the body and a pairs of cornua, the greater and the lesser cornua ${ }^{(9)}$.

Body: The body is irregular, elongated and quadrilateral. Its anterior surface is convex, faces anterosuperiorly and is crossed by a transverse ridge with a slight downward convexity. A vertical median ridge often bisects the upper part of the body, but rarely extends to the lower part. The posterior surface is smooth, concave, faces posterioinferiorly, and is separated from the epiglottis by the thyrohyoid membrane and loose areolar tissue, there is a bursa between the hyoid bone and the membrane ${ }^{(9)}$.

Greater cornua: In early life, the greater cornua are connected to the body by cartilage, but after middle age they are usually united by bone. They project backwards (curving posterolaterally) from the lateral ends of the body. They are horizontally flattened, taper posteriorly, and each ends in a tubercle, when the throat is gripped between finger and thumbs above the thyroid cartilage, the greater cornua can be identified and the bone can be moved from side to side ${ }^{(9)}$.

Lesser cornua: The lesser cornua are two small conical projections at the junctions of the body and greater cornua. At its base, each is connected to the body by fibrous tissue and occasionally to the greater cornu by asynovial joint which occasionally becomes ankylosed ${ }^{(9) .}$

Development of the hyoid bone: The hyoid bone develops from cartilages of the second and third pharyngeal arches, the lesser cornua from the second, the greater cornua from the third and body from the fused ventral ends of both. Chondrification begins in the fifth fetal week in these elements and is completed in the third and fourth months ${ }^{(9)}$.

Ossification: Ossification proceeds from six centeres i.e., a pair for the body and one for each cornu. Ossification begins in the greater cornua towards the end of intrauterine life, in the body shortly before or after birth, and in the lesser cornua around puberty. The greater cornual apices remain cartilaginous until the third decade and epiphyses may occur here. They fuse with the body. Synovial joints between the greater and lesser cornua may be obliterated by ossification in later decades ${ }^{(9)}$.

The metric analysis of the hyoid bone is helpful technique in the sex determination of a skeleton ${ }^{(1)}$. The present authors developed interest in studying the hyoid bone by using the various parameters.

Purpose of the Hyoid Bone: The hyoid bone serves a number of purposes. The first is to provide a place of attachment for a number of anterior neck muscles including the sternohyoid, mylohyoid, omohyoid, digastric 
muscles and more. These and other anterior neck muscles play a role in swallowing and can be greatly affected in cases of neck injuries or misalignment. The hyoid also provides a foundation or base from which the tongue can move. It is involved in respiration, as well. The second purpose of the hyoid is to help prop the airway open (4)

\section{Meterial and methods}

The material for the present study include 83 specimens of the hyoid bones collected from the cadavers during autopsies of Osmania General Hospital, Hyderabad from 2010 - 2013. The specimens were selected out of 350 medico legal cases in the age group of 15 - 75 years. Some of the hyoid bones obtained were damaged particularly those of hanging and strangulation cases. So, they were excluded from the present study. Before starting the autopsy, age and sex of the cadaver was recorded. Then autopsy was done to mobilize and remove the hyoid bone from the body. The traditional method described in the text book of autopsy diagnosis and technique by Otto Saphir ${ }^{(5)}$ was adapted.

The following measurements were taken with the help of Vernier Caliper (1 to 3 parameters are in $\mathrm{mm}$ ) and electronic weighing machine ( $4^{\text {th }}$ parameter in grams).

1. Length of the greater cornu - right.

2. Length of the greater cornu - left.

3. Distance between the upper and lower margins of the body (height).

4. Weight after defatting.

Data was designed on a master chart and analysed statistically using the standard statistical method.

\section{Results}

In the present study with a sample size of 83 bones which includes 56 male and 27 female. In the age group, 0 to 20 years male, 0 to 10 and 61 to 70 years female bones were not found. According to the age the

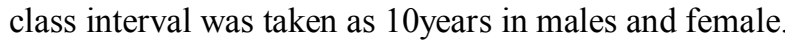

Table: 1 showing the male values

\begin{tabular}{|l|l|l|l|l|l|}
\hline Age & No of males & $\begin{array}{l}\text { Mean } \pm \text { SD(right) } \\
(\mathrm{mm}) \text { parameter1 }\end{array}$ & $\begin{array}{l}\text { Mean } \pm \mathrm{SD}(\mathrm{left}) \\
(\mathrm{mm}) \text { parameter2 }\end{array}$ & $\begin{array}{l}\text { Mean } \pm \mathrm{SD}(\mathrm{mm}) \\
\text { parameter3 }\end{array}$ & $\begin{array}{l}\text { Mean }+\mathrm{SD}(\mathrm{gm}) \\
\text { parameter4 }\end{array}$ \\
\hline $21-30$ & 4 & $33.8 \pm 3.03$ & $32.62 \pm 1.6$ & $15 \pm 2.3$ & $1.28 \pm 0.48$ \\
\hline $31-40$ & 13 & $32.1 \pm 2.07$ & $32.34 \pm 2.29$ & $12.1 \pm 0.7$ & $1.067 \pm 0.29$ \\
\hline $41-50$ & 18 & $32.3 \pm 2.08$ & $32.2 \pm 2.15$ & $12 \pm 1.07$ & $0.9869 \pm 0.204$ \\
\hline $51-60$ & 13 & $31.7 \pm 2.06$ & $31.7 \pm 2.17$ & $10.3 \pm 1$ & $0.9334 \pm 0.199$ \\
\hline $61-70$ & 8 & $31.1 \pm 0.88$ & $31.1 \pm 0.88$ & $11.7 \pm 0.88$ & $0.870 \pm 0.114$ \\
\hline
\end{tabular}

Table: 2 showing the female values

\begin{tabular}{|c|c|c|c|c|c|}
\hline Age & $\begin{array}{l}\text { No of } \\
\text { females }\end{array}$ & $\begin{array}{l}\text { Mean } \\
(\text { right })(\mathrm{mm}) \text { parameter1 }\end{array}$ & $\begin{array}{l}\text { Mean } \pm S D(\text { left }) \\
(\mathrm{mm}) \text { parameter2 }\end{array}$ & $\begin{array}{ll}\text { (Mean } & \pm \\
\mathrm{SD}(\mathrm{mm}) \text { parameter3 } & \pm\end{array}$ & $\begin{array}{l}\text { Mean } \\
\mathrm{SD}(\mathrm{gm}) \text { parameter }\end{array}$ \\
\hline $21-30$ & 5 & $25.4 \pm 2.58$ & $25.4 \pm 2.58$ & 10 & $0.645 \pm 0.065$ \\
\hline $31-40$ & 6 & $30.7 \pm 1.75$ & $30.7 \pm 1.75$ & $10.6 \pm 0.6$ & $0.8328 \pm 0.075$ \\
\hline $41-50$ & 2 & 28 & 28 & $8.5 \pm 2.12$ & $0.6725+0.024$ \\
\hline $51-60$ & 11 & $28.9 \pm 1.64$ & $29.31 \pm 1.47$ & $10.13 \pm 1.18$ & $0.7403 \pm 0.09$ \\
\hline $61-70$ & 3 & $30.16 \pm 0.28$ & $28.16+0.28$ & $9.16+0.28$ & $0.58+0.068$ \\
\hline
\end{tabular}

\section{Discussion}

In the present study we can estimate the age of the hyoids, mainly in males when compared to females. According to Ranjith and Pillai $S^{(7)}$ the mean weight of the hyoid bone in male was $1474.40 \pm$ $289.66 \mathrm{mg}$ and that of the female hyoid bone was $960 \pm 233.37 \mathrm{mg}$. In this study only estimation the sex was possible. In the year 1996 Harjeet and Jit I ${ }^{(3)}$ have compared the age of the cadaver and weight of the hyoid bone and found that significant correlationship existed between them in males. In males, the weight of the hyoid bone after defatting increased from $0.2 \pm 0.04 \mathrm{~g}$ at the age of 4 years to $0.9 \pm 0.07 \mathrm{~g}$ at the 17 years and was $1.45 \pm$ $0.41 \mathrm{~g}$ in the age group of $41-45$ years. Thereafter it decreased progressively and was found to be $1.22 \pm 0.27 \mathrm{~g}$ in the age group of 61-80 years. Similarly in females, the weight after defatting increased from $0.23 \pm 0.05 \mathrm{~g}$ at 3 years to $0.7 \pm 0.14 \mathrm{~g}$ at the age of 17 years, it further increased to $0.95 \pm 0.31 \mathrm{~g}$ in the age group of $41-45$ years. Thereafter it continued to decrease and was found to be $0.80 \pm 0.168 \mathrm{~g}$ in the age group of $61-80$ years.

In the present study: (a) The mean weight after defatting in males is 1.28 grams in 21 to 30 years age group, it decreases to 1.067 grams in 31 to 40 years age group, decreases to 0.9869 grams in 41 to 50 years age group, decreases to 0.9334 grams in 51 to 60 years age group and then finally decreases to 0.870 grams in 61 to 70 years age group. In females is 0.645 grams in 11 to 20 years age group, it increases to 0.8328 grams in 21 to 30 years age group, decreases to 0.6725 grams in 31 to 40 years age group, increases to 0.7403 grams in 41 to50 
years age group and then finally decreases to 0.58 grams in 51 to 60years age group. This suggests that the use of this parameter of the hyoid bone to estimate the age only in males.

(b) The mean length of the greater cornu of males (right) is $33.8 \mathrm{~mm}$ in 21 to 30 years age group, it decreases to $32.1 \mathrm{~mm}$ in 31 to 40 years age group, increases to $32.3 \mathrm{~mm}$ in 41 to 50 years, decreases to $31.7 \mathrm{~mm}$ in 51 to 60 years age group and then finally decreases to $31.1 \mathrm{~mm}$ in 61 to 70 years age group.The mean length of the greater cornu of males (left) is $32.62 \mathrm{~mm}$ in 21 to 30 years age group, it decreases to $32.34 \mathrm{~mm}$ in 31 to 40 years age group, decreases to $32.2 \mathrm{~mm}$ in 41 to 50 years, decreases to $31.7 \mathrm{~mm}$ in 51 to 60 years age group and then finally decreases to $31.1 \mathrm{~mm}$ in 61 to 70 years age group.

(c) The mean length of the greater cornu of females (right) is $25.4 \mathrm{~mm}$ in 11 to 20 years age group, it increases to $30.7 \mathrm{~mm}$ in 21 to 30 years age group, decreases to $28 \mathrm{~mm}$ in 31 to 40 years, increases to $28.9 \mathrm{~mm}$ in 41 to 50 years age group and then finally increases to $30.16 \mathrm{~mm}$ in 51 to 60 years age group. The mean length of the greater cornu of females (left) is $25.4 \mathrm{~mm}$ in 11 to 20 years age group, it increases to $30.7 \mathrm{~mm}$ in 21 to 30 years age group, decreases to $28 \mathrm{~mm}$ in 31 to 40 years, increases to $29.31 \mathrm{~mm}$ in 41 to 50 years age group and then finally decreases to $28.16 \mathrm{~mm}$ in 51 to 60 years age group. The Present Study is not correlating with Seham A. Gad EL. Hak et al ${ }^{(8)}$. According to his study the length of greater cornua is increasing with age.

In the present study the length of greater cornua is not increasing progressively with age. In male hyoids the length is decreasing, in female hyoids the estimation of age may be unconventional.

The mean distance between the upper and lower margins of the body in males is $15 \mathrm{~mm}$ in 21 to 30 years age group, it decreases to $12.1 \mathrm{~mm}$ in 31 to 40 years age group, decreases to $12 \mathrm{~mm}$ in 41 to 50 years age group, decreases to $10.3 \mathrm{~mm}$ in 51 to 60 years age group and then finally increases to $11.7 \mathrm{~mm}$ in 61 to 70 years age group. The mean distance between the upper and lower margins of the body in females is $10 \mathrm{~mm}$ in 11 to 20 years age group, it increases to $10.6 \mathrm{~mm}$ in 21 to 30 years age group, decreases to $8.5 \mathrm{~mm}$ in 31 to 40 years age group, increases to $10.13 \mathrm{~mm}$ in 41 to 50 years age group and then finally decreases to $9.16 \mathrm{~mm}$ in 51 to 60 years age group. No literature is available for the determination of the age by using this parameter. In the present study use of the hyoid bone to estimate the age with the height is possible in males but in females this may be unconventional.

With the help of anthropometric measurements of the following parameters- length of the greater cornua- right and left, height\& weight after defatting, in the present study age can be determined in male hyoids. And it can be determined by looking at the ossification center and there fusion ${ }^{2,6,8 \& 10}$ with the help of radiological images which was not included in the present study.

The Mean, Standard deviation and level of significance of all the four parameters of the hyoid bone were calculated using the standard statistical method. The readings of mean \pm S.D of different parameters are statistically significant $(\mathrm{p}<0.001)$.

\section{Conclusion}

Regarding the estimation of the age of the bone the authors were tried with different anthropometric parameters whether the age could be estimated. But we can estimate the age in male hyoids with these parameters.

\section{Acknowledgement}

I express my sincere thanks to Dr. Ramagalla parameshwar. Who is solely responsible, to initiate and complete my research work.

\section{References}

[1]. E.M.Reesink, A. A. H. Van Immerseel, R. Brand, Tj. D. Bruintjes; 1999: International Journal osteoorchaeol, 9(5): 357-360.

[2]. Gupta A, Kohli A, Aggarwal NK, Banerjee KK; Study of Age of fusion of hyoid bone - Journal of Leg med (Tokyo), 2008 Sep10 (5): $253-6$

[3]. Harjeet and Jit I; 1996: Shape, Size and Sexual dimorphism of the hyoid bone in northwest Indians. Journal of Anatomical Society of India. Vol.45 (1): 4-22.

[4]. Moore, K, Dalley, A. Clinically Oriented Anatomy. Fifth Edition. Lippincott, Williams\& Wilkins. 2006. Baltimore.

[5]. Otto Saphire (1958): $4^{\text {th }}$ edition. The text book of Autopsy Diagnosis and Technique.

[6]. Pollanen MS, Chaisson DA; 1996: Fracture of the hyoid bone in strangulation: Comparison of fractured and unfractured hyoid from victims of strangulation. Journal of Forensic Science. 41(1):110-113.

[7]. Ranjith and Pillai S; 1988: A Post mortem study of 100 hyoid bones using weight as parameter. Journal of Indian Academy of Forensic Medicine. 10: 31-33.

[8]. Seham A. Gad El. Hak; Sahar A. El. Dakroory; Adel A. El. Hawary and Amr M. Alghazally; 2007: Sexual Dimorphism of the hyoid bone. A primary study - Journal of Forensic Med. Clin. Toxicol. Vol. XV, No.1.

[9]. Susan Standring et al; 2008: Text book of Grays Anatomy $-40^{\text {th }}$ edition - Gross Anatomy- Celsevier, Churchill. Livingstone.

[10]. Ubelaker DH (1992): Hyoid fracture and strangulation-J Forensic sci. 37(5): 1216-22. 